\title{
Ideological Mind-Shaping or Brain-Shaping: Fusing Empirical Biopolitics and Political Philosophy of Mind
}

\author{
Leor Zmigrod $^{1}$ \\ ${ }^{1}$ Department of Psychology, University of Cambridge
}

This is a preprint of a paper in press at the Journal of Philosophy of Emotion, due to be published in 2022. For any questions or queries, please contact Dr Leor Zmigrod at lz343@cam.ac.uk. The paper can be cited as:

Zmigrod, L. (2022). Ideological Mind-Shaping or Brain-Shaping: Fusing Empirical Biopolitics and Political Philosophy of Mind. Journal of Philosophy of Emotion.

"Every relationship of forces constitutes a body - whether it is chemical, biological, social or political" (Deleuze, 1962/2006, p.37)

$* * *$

\section{Introduction}

There are two primary philosophical approaches to examining the relationship between human bodies and political bodies. The first, reflected in traditional political theory on the 'body politic', is concerned with the question of how individuals aggregate into functioning or malfunctioning collectives - how singular citizen bodies come to constitute wider political entities. The second approach, maturing later in $20^{\text {th }}$ century social and political philosophy, considers the opposite relation; instead of evaluating how the body politic emerges from the bottom-up, it focuses on how bodies become politicized from the top-down. This, more sociological, perspective explores how human bodies are disciplined and learn to selfdiscipline into particular physical forms and functions. Dominant ideologies can infiltrate the bodies of adherents, and the task of the social critic or political philosopher is to delineate how, why, where, and when political structures shape the minds and bodies of citizens - as well as whether the effects are coercive, destructive, or liberatory. 
I will argue that a political philosophy of mind cannot flourish without attention to the cognitive science of ideologies. Until recently there has been little serious dialogue between biology and political philosophy, partly due to disciplinary balkanization and mostly because of the infancy of empirical biopolitics, the science of how cognitive and neurobiological processes are molded by political ideologies. I will suggest that attending to the emerging science of ideological cognition can allow us to build a stronger, more compelling, and provocative thesis on the mind-shaping consequences of immersion in ideologies than is possible with conceptual tools alone.

The argument will proceed as follows. Firstly, I will briefly review how political philosophy has conceptualized the politicization of bodies and embodiment of ideology. Social theorists, from Michel Foucault to Maurice Merleau-Ponty and Frantz Fanon, Hannah Arendt to Sally Haslanger and Victoria McGeer, have argued that ideological discipline and oppression change human beings through explicit control and self-control as well as through implicit transformations of self-perception, phenomenology, and moral epistemology. In other words, ideologies influence social beliefs, agency, and experience in everyday social interactions. Indeed, ideology is often invoked to explain why individuals often accept and justify - and sometimes advocate for - unjust social arrangements that can lead to their own oppression (Bianchin, 2021; Celikates, 2017; Haslanger, 2017; Jaeggi, 2008; Jost, 2020; Piketty, 2020; Sankaran, 2020; Stanley, 2015). Nevertheless, despite a close attention to embodiment and mind-shaping processes, these theoretical accounts have largely constrained the origins and consequences of ideological thinking to the social realm of intersubjectivity. When an individual navigates the social world, the effects of ideological discipline and oppression become clear in how they steer and respond to interpersonal relationships, exchanges, and the negotiation of subjective identity. Sociality and subjectivity are at the heart of these philosophical accounts. Yet it is also possible that we can observe the constitutive effects of ideologies on minds and bodies in domains that are not directly concerned with social exchange or subjectivity.

In The Mind-Body Politic, Maise and Hanna (2019) make essential steps forward by acknowledging that while political socialization is key, the reverberations of ideologies can go far into the body and mind, including physical movement, sensation, affective orientation, and attentional habits. In Maise and Hanna's account, political philosophy and ideology critique are merged with an understanding of habits of mind. The Mind-Body Politic emphasizes that ideological institutions, in particular institutions tinged by neoliberalism, determine beliefs, 
behaviors, and self-consciousness in real and literal ways. The effects are not metaphorical they can be identified, enumerated, and traced to the physicality of the body. The repetitive practice of neoliberal habits becomes embodied and embedded.

Firstly, I will argue that neoliberalism may not be an ideal candidate upon which to build an empirically-grounded political philosophy of mind because, in contrast to other ideological doctrines, neoliberalism is less tractable to define, measure, analyze comparatively, and critique. Moreover, I will build upon the Neurocognitive Model of Ideological Thinking (Zmigrod, 2021) and extend Maise and Hanna's (2019) Mind-Shaping Thesis to argue that we can form an even "deeper" thesis about the penetration of ideologies into perception, cognition, and behavior. Drawing on the latest research in political neuroscience and political psychology, I will evaluate research demonstrating that ideological doctrines may shape cognitive and perceptual domains which are principally asocial. The effects of ideological immersion can cascade into non-political and non-social psychological domains of basic human perception and cognition. We can observe these consequences empirically; dogmatic adherents to ideological doctrines respond to neutral perceptual stimuli and decision-making tasks in ways that are systematically different to moderates and non-ideological citizens. This suggests that we can postulate a deeper and more mechanistic hypothesis about how ideologies shape the brains of followers and structure their consciousness, phenomenology, and epistemology.

\section{Politicized Bodies: Biopower, Embodiment, and Phenomenology}

To understand the depth and reach of both the Neurocognitive Model of Ideological Thinking (Zmigrod, 2021) and Maise and Hanna's Mind-Shaping Thesis, it is necessary to distinguish these from other claims surrounding the politicization of human minds and bodies. Michel Foucault coined the term 'biopower' to denote the ways in which power by the state and institutions can regulate life by disciplining bodies in prisons, armies, medical institutions, factories, and schools. In this "anatomo-politics of the human body" (Foucault, 1978, p.139), bodies are tactically, gradually, and aggregately trained to maximize social utility and docility. Deviation is minimized by discipline, punishment, and specific reward structures. Biopower centres "on the body as a machine: its disciplining, the optimization of its capabilities, the extortion of its forces, the parallel increase of its usefulness and its docility, its integration into systems of efficient and economic controls" (Foucault, 1978, p.139). Foucault (1993) observes that governance translates into self-governance. Coercive techniques to control individuals 
cascade into how citizens come to construct and control themselves (i.e. 'subjectivation'). The effects of ideological discipline on the human body are therefore tangible and self-reinforcing. Foucault's emphasis is on the explicit changes to the exterior physical body that take place through the internalization of social norms surrounding discipline and docility. So although biopower reflects ideologies about human bodies, it is a theory that does not attend to the human brain as such or about what disparate ideologies can do to human brains.

Other philosophical accounts have considered the embodiment of ideology and phenomenological character of being immersed in an ideologically dogmatic or hostile environment. This is particularly clear in the misogynistic, racist, ableist, capitalist, xenophobic, fundamentalist, and heteronormative assumptions of what bodies are expected to do or look like (e.g. Alcoff, 2006; Bartky, 1990; Haslanger, 2019). At the broadest interpretation, Merleau-Ponty identified that human beings learn to see and feel, and then come to adopt sedimented physical and psychological habits that shape and are shaped by social experiences. He noted in the Phenomenology of Perception: "I am a psychological and historical structure. Along with existence, I received a way of existing, or a style. All of my actions and thoughts are related to this structure (Merleau-Ponty, 1945/2012, p.482).

Racialization is one potent instance of ideology, embodiment, and phenomenology coming into contact. As Frantz Fanon observed in Black Sin, White Masks, "In the white world the man of color encounters difficulties in the development of his bodily schema... Below the corporeal schema I had sketched a historical-racial schema" (Fanon, 1967/2008, p.83). Linda Martín Alcoff elaborated on Merleau-Ponty and Fanon's ideas to argue that racialization partially determines our vision and representations of bodies:

"Merleau-Ponty is mainly discussing motor habits of perception and movement used in performing various operations such as driving or typing, but the concept can easily be applied to postural attitudes and modes of perception taken in interactions with others whose identities are marked by gender, race, age, and so on. Following Fanon [1967], Gordon [1995], and Weiss [1998], I will also argue that racialization structures the visual sphere and the imaginary self, and can block the development of coherent body images." (Alcoff, 2006, p.184)

Alia Al-Saji (2014) extends this to demonstrate how these phenomenological features originate in - and justify - oppressive ideologies: 
"A primary way in which racialization takes hold in lived experience, while remaining unconscious and invisible, is by means of perception... The seeming naturalness of perceived "race"-categories works to justify the very racist logic that produced them" (Al-Saji, 2014, p.137).

The embodiment of ideology, such as racism, is thus tightly linked to our bodily and social subjectivity and can facilitate the perpetuation of ideological oppression and injustice. In the spirit of a political philosophy of mind, these theoretical analyses focus on the ways in which bodies are politicized and shaped by social institutions and prevailing ideologies. Yet the focus is still bound to the domains of sociality, subjectivity, and intersubjectivity. The claim of The Mind-Body Politic (Maise \& Hanna, 2019) and the Neurocognitive Model of Ideological Thinking (Zmigrod, 2021) is that ideological institutions and doctrines can shape the minds of adherents beyond the domains of social perception and self-perception. Ideologies can shape how adherents perceive any stimuli and respond to any decision context - the psychological effects are not restricted to the social realm. The thesis is thus "deeper" in the sense that the ideological penetration of perception and cognition reaches further than most contemporary philosophical accounts. In addition, this thesis is more "mechanistic" and prone to empirical inquiry; the natural sciences of biology and neuroscience can examine whether these phenomena are manifest when using objective scientific assessments. But before we turn to the experimental evidence, it is essential to identify what counts as a "mind-shaping ideology" and which ideologies are the best candidates for advancing an empirically-grounded political philosophy of mind.

\section{Mind-Shaping Ideologies}

As evident from its title, Maise and Hanna's (2019) The Mind-Body Politic implicitly knits together two old philosophical debates: (1) the mind-body problem, the question of whether and how mental and physical matter interact, and (2) the concept of the body politic, debates on the form and function of political entities, including the degree to which these are akin to biological bodies. These debates are brought together in their Mind-Shaping Thesis, which postulates that

"All social institutions saliently constrain, frame, and partially determine the socialdynamic patterns of our essentially embodied consciousness, self-consciousness, affect 
(including feelings, desires, and emotions), cognition, and agency - that is, they literally shape our essentially embodied minds, and thereby fundamentally affect our lives, for worse or better, mostly without our self-conscious awareness.” (Maise \& Hanna, 2019, p.8)

For Maise and Hanna, it is because we are "social minded human animals" that our minds are "partially determined, and literally shaped, by the social institutions we belong to, participate in, or fall under the jurisdiction of, in contemporary neoliberal societies" (2019, p.37). Notably, they argue that "the mind-shaping here is not just notional or metaphorical; it is literal and happening literally" (emphasis in original, p.9).

How does the mind-shaping process take place? Maise and Hanna rightly and fruitfully turn to the psychology of learning and habit-formation. Drawing on Bourdieu's (1977) concept of habitus and Proveti's (2009) work on how "a body is patterned by the social system into which it is acculturated" (2009, p.32), Maise and Hanna consider how norms become habitualized and hence embodied, such that "many of the habits developed within social institutions can be understood as bodily skills" (2019, p.46).

"Cultural expectations solicit certain forms of action and experience, particular sequences of thought and action become routine, and these habitualized patterns are ratified and reinforced by way of institutional norms and social approval. Thus, various aspects of the socio-cultural environment play a crucial role in the formation of an embodied subject's characteristic patterns of attention, engagement, and response." (Maise \& Hanna, 2019, p.54)

Furthermore as Maise (2021) later elaborates,

"Via the entrainment of brain and bodily dynamics and the formation of habits, there is a genuine sense in which we internalize social influences and norms, so that our living bodies become "socially saturated" and socio-normatively laden... However, precisely because the way in which we are socially situated molds the way in which behave and interpret things, our patterns of action and attention can become overdetermined by social relations and structures." (Maise, 2021, p.2)

In demarcating that the mind-shaping process is one of habits of attention, affect, and bodily movement, Maise and Hanna are delving deeper than many mind-shaping accounts, which are overly general. The original formulation of mind-shaping by Matteo Mameli defined a 
"mindshaping effect [as] an effect on the development or structure of a mind" (Mameli, 2001, p.608). This definition is fairly shallow from a neurocognitive perspective - it makes no deep or mechanistic claims about what, other than broad belief or behaviour, is shaped in mindshaping:

"The mindshaper interacts with the mindshaped subject on the basis of his beliefs about the subject. These beliefs may or may not be true. Whether they are true or not, they have important effects on the interaction between the mindshaper and the target and, thereby, on the target's mind. Here is an example. Because of the tacit assumptions generated by their gender stereotypes, people treat males and females very differently throughout life. This causes males and females to interact with systematically different kinds of environmental and social conditions. And these systematic differences cause systematic differences in the average behavior of males and females." (Mameli, 2001, p.614)

In these examples, mind-shaping is reducible to (social) learning and socialization, which is passed down in ways that shape future generations' environments. The Mind-Body Politic demonstrates an awareness that we can be more specific about what is shaped by mind-shaping ideologies and how this occurs. Yet when it comes to arguing that neoliberal ideologies and institutions are mind-shaping, the mechanisms of action are not very clear, precise, or empirically grounded. I argue that such processes can be elucidated if we (1) shift away the focus from neoliberal ideologies to other ideological doctrines, and (2) rely on the new empirical biopolitics to delineate mechanisms that are tractable, reasonable, and specific enough to constitute an explanatory theory.

\section{Tractability of Theoretical, Empirical, and Critical Analysis}

Several of the most compelling questions that could be addressed by a political philosophy of mind include: How do political ideologies transform the cognitive and biological constitution of their adherents? What (political) force would need to be applied to human brains in order for such a change to occur? And, notably, in what mental domains would the reverberations of this force be manifest? In other words, how far into human cognition and perception - and away from the original domain of politics - can we find the residues of ideological thinking? 
One of the challenges of The Mind-Body Politic is that, while it is interested in unpacking some of these questions, its central focus is neoliberal institutions. I believe that this leads to three kinds of problems: (1) conceptual, (2) empirical, and (3) critical, that is, in the service of the aims of social critique.

Firstly, neoliberalism is vaguely defined in terms of Hobbesian liberalism, capitalism, and technocracy, and institutions are granted a "maximally broad conception" (p.5) which encompasses almost every kind of social grouping from the family to sports groups to workplaces to nation-states. Maise and Hanna argue that neoliberalism is so deeply ingrained in our social fabric, we can barely perceive its contours. Yet this means that, from a psychological perspective, it is unclear what a "neoliberal mind" looks like. It is ill-defined and with few comparison points. As I argue elsewhere (Zmigrod, 2022), ideological thinking necessitates an ideological doctrine - with a set of prescriptive and descriptive beliefs - and a parochial relational orientation that is strongly favorable to ingroup members and antagonistic and hostile towards non-believers. It is difficult to definitively identify "neoliberal ideological thinking"; what is the doctrine and who are its adherents and non-adherents? Ideologies such as nationalism, social conservatism, or religious ideologies have a more well-defined structure and psychological character. Hence, from a conceptual perspective, neoliberalism is not an ideal candidate for tracing the cognitive antecedents and consequences of ideological institutions.

Secondly, because of neoliberalism's pervasiveness and embeddedness in modern societies, it is challenging to envision an empirical study of the cognitive and affective habits of neoliberalism. Scientific inquiry and analysis require comparison points. These comparison points can be temporal (before and after a certain condition) or cross-sectional (between case A and case B). Yet with the embodiment of neoliberalism, there are few identifiable comparisons. Indeed, Maise and Hanna (2019) note that neoliberal attitudes "have gained such a strong grip and become so thoroughly internalized that in all likelihood they will continue to exert a significant residual influence even after someone has subjected them to serious critical scrutiny" (p.27). It is nearly impossible to empirically study the psychological origins or effects of an 'inescapable' ideology. The most interesting political, philosophical, and psychological questions rest with ideologies where there is, at least to a certain degree, a "genuine option" in William James' (1896) terminology. A "genuine option" exists when (1) there are multiple plausible options for belief and action, (2) choosing belief or non-belief cannot be avoided, and (3) the option is momentous such that the stakes are significant and the choice is not easily 
reversible (James, 1896). The adoption or rejection of neoliberal ideologies is rarely a "genuine option" in this regard. As a result, one of the principal limitations, in my view, of The MindBody Politic is that it concerns an 'ideology' that is so ubiquitous and institutionalized that, for most individuals, it is not an ideology that is genuinely chosen or one that individuals (feel) can be left or moved away from. Neoliberalism is therefore difficult to measure, assess, or capture in a way that would lend itself towards falsifiable theories. This is a serious limitation.

One may argue that a political philosophy of mind - or any social theory for that matter - does not to be constrained by empirical science. Some may be broadly opposed to philosophical naturalism, specifically the notion that where the concerns of science and philosophy overlap, science should guide or at least constrain philosophical inquiry (Price, 2004). However, mindshaping accounts are not merely theoretical - they have practical consequences for ideology critique (Haslinger, 2020; McGeer, 2020). As Victoria McGeer observes: “it's only by understanding how our minds are shaped through enculturation that we can make real progress in understanding the resilience of practices of injustice (even those that are recognized), as well as developing better strategies for resisting and remedying them" (2020, p.49). Elucidating mechanisms, and ensuring that these are consistent with the science of the mind and society, is key for an emancipatory political philosophy of mind. It unearths the cognitive processes that perpetuate oppression and allows us to envision antidotes. Furthermore, a noted challenge for ideology critique is the epistemic positionality of the critic - how can they identify and judge the nature of the ideology's oppressions if they are viewing it from inside? Maise and Hanna reflectively point to the notion that "neoliberal ways of thinking, feeling, speaking, and acting have become so ingrained that they typically are accepted unreflectively and without question, even for scholars who have devoted their careers to studying the harmful impact of other toxic ideologies" (p.27). Examining the mind-body-politic dynamics of ideological doctrines which are more narrowly defined, as well as less insidious and unavoidable, may bolster the epistemic capabilities of critics.

In sum, neoliberalism is a suboptimal choice for building a sound political philosophy of mind from conceptual, empirical, and critical perspectives. In order to evaluate how (and which) ideologies are brain-shaping in meaningful and dangerous ways, we must complement philosophical inquiry with empirical biopolitics. 


\section{Neurocognitive Model of Ideological Thinking: Mechanisms of Mind-Body- Politic Interactions}

The Neurocognitive Model of Ideological Thinking (Zmigrod, 2021) offers a theoretical framework for understanding how and why individuals are dragged into, or plunge themselves toward, toxic ideologies. It begins from the premise that we can outline what constitutes 'ideological thinking' by studying the degree to which an ideology is adhered to with epistemic dogmatism and interpersonal intolerance (Zmigrod, 2022). Notably, being immersed in an ideology is a more specific phenomenon than mere enculturation. Knowledge of the mental antecedents and consequences of ideological thinking can be best developed when we can compare 'strong' and 'weak' adherents of an ideology or compare the functioning of multiple ideologies. Individuals are more ideological extreme if they exhibit the characteristics of epistemic dogmatism and interpersonal intolerance to a greater degree than others, whereas ideological moderates exhibit receptivity to evidence and a humanism that negates an 'us' versus 'them' mentality. In other words, regardless of the ideology at hand, ideological thinking possesses a certain structure than can be identified across different ideologies. Unpacking the contribution of the substance of an ideology - i.e. its aims and claims - must come after the structure of the ideology has been mapped. When hegemony eliminates nuance and variation, it is difficult to conceptually or empirically compare gradients of ideological thinking.

The Neurocognitive Model of Ideological Thinking postulates that there are bidirectional links between the brain and the ideology it is immersed in. Firstly, there are neurocognitive antecedents in individuals' brains that shape their tendencies towards ideological thinking. Secondly, there can also be neurocognitive consequences to strong immersion in ideological environments.

This is exemplified and supported by empirical findings that individuals with certain ideological proclivities are characterized by particular neurocognitive traits. For instance, individuals who are more ideologically extreme or dogmatic or prone to violent solutions tend to exhibit cognitive rigidity on neutral neuropsychological tests (Zmigrod, 2020; Zmigrod et al., 2018, 2019, 2019, 2020). In these tests, participants are responding to changing response rules, such as sorting a deck of cards according to the colour of the cards, and then the rule changes; cognitively flexible participants will adapt to the new rule whereas rigid participants will maladaptively persevere with the previous learned rule. It is striking that cognitive rigidity on these types of neuropsychological tasks are associated with the degree to which an 
individual is ideologically rigid and dogmatic. Two non-exclusive processes may be at play (Zmigrod, 2021): cognitively rigid individuals may gravitate towards more rigid interpretations of an ideology (i.e. the mind is antecedent to politics) and/or strong immersion in an ideology leads to more cognitively rigid minds across psychological domains (i.e. politics precedes the $\operatorname{mind})$.

Similar patterns of ideology-cognition couplings are evident in other psychological traits. For instance, Zmigrod and colleagues (2021) gave over 350 participants a large battery of psychological tests, including behaviourally-assessed cognitive tasks and self-reported personality surveys, as well as ideological attitudes questionnaires. Through data-driven approaches, Zmigrod and colleagues (2021) found that resonances between visual perception and ideology emerged. As part of this study, participants were given perceptual decisionmaking tasks, such as tasks that asked them to indicate whether dots on the screen were moving to the left or to the right. The instructions asked participants to respond as quickly and as accurately as possible, thus prioritizing both speed and accuracy. Individuals who were most perceptually cautious on these tasks, meaning that they preferred to respond slowly-butaccurately rather than quickly-but-erroneously, tended to be more politically conservative (Zmigrod et al., 2021). Hence, individuals with more conservative and cautious ideologies displayed more caution even at the level of visual perception (Zmigrod, 2021, 2022, under review). Phenomenologically, this raises many fascinating questions: do perceptual preferences for caution yield political preferences for conservatism? Or does the experience of social conservatism, with its emphasis on tradition in social life, lead to preferences for conservative strategies even in non-political and non-social domains?

Although disentangling the causal directionality is an important next step (Zmigrod, 2020, 2021, 2022, under review; Zmigrod \& Tsakiris, 2021), these empirical results signify that the depth of ideological mind-shaping may extend beyond purely the social - it may penetrate the asocial, including cognitive and perceptual architecture. Political philosophy of mind can thus benefit enormously from these types of empirical elucidations, which help to both constrain and expand the scope of what the field can hypothesize and which political issues it can speak to. 


\section{Conclusions: Habits of Mind, Ideological Brain-Shaping, and Social Critique}

At the core of political philosophy as well as philosophy of mind are questions on what and who governs us, and what part of 'us' is being governed. In The Mind-Body Politic, Maise and Hanna (2019) build on core work in social theory centring on the role of embodied habits of mind; because we are habitual creatures, we absorb social norms and ritualize them, and hence politics becomes patterned into our social habits. Yet the focus of mind-shaping accounts on broad social norms, culture, and neoliberalism are too vague and neurocognitively shallow to be empirically tractable or meaningful. Advances in political psychology and neuroscience illustrate that in fact ideological doctrines may have consequences that extend beyond the social domain and bleed into the general perceptual and cognitive functioning of adherents (Zmigrod, 2021, 2022, under review). To get at the mechanisms that govern these processes, we may need to emphasize ideological brain-shaping, as opposed to the fuzzier mind-shaping. It will be imperative to consult the psychological and neurobiological literature to delineate the processes and interactions that govern minds and bodies entrenched in (or resisting!) ideological environments. Hence, it is necessary to fuse empirical biopolitics with the emergent discipline of political philosophy of mind.

Updating philosophical theories in response to scientific elucidations is not merely conceptually advantageous - it is necessary for a genuinely emancipatory political theory that can help instigate change and identify routes to justice and liberation from toxic authoritarian ideologies. As Jan Slaby (2016) observes, “The question of the constitution of individual mental capacities is here inseparable from the question of a normatively adequate organization of socio-political reality at large — where "normatively adequate" here means, at the very least: worthy of reflective endorsement by those concerned" (p.7). Ideology critique necessitates that we dissect exactly how ideological doctrines coerce the mind and how cognition mutates under the seductions of ideological dogmas and groups. Delineating the nature of these neuropsychological changes, including their longevity, depth, and reversibility, is a task of urgency both to the psychologist and the philosopher. Resisting ideological oppressions requires that we grasp how our minds change in response to these coercions, and what feasible, effective, and ethical antidotes may look like. 


\section{References}

Alcoff, L. (2006). Visible identities. New York: Oxford University Press.

Al-Saji, A. (2014). A phenomenology of hesitation: Interrupting racializing habits of seeing. In E. S. Lee (Ed.), Living alterities: Phenomenology, embodiment, and race (pp. 133-172). Albany: State University of New York Press.

Bianchin, M. (2021). Ideology, Critique, and Social Structures. Critical horizons, 22(2), 184196.

Celikates, R. (2017). Critique and resistance: Ethical, social-theoretical, political? On Fabian Freyenhagen's Adorno's practical philosophy. European Journal of Philosophy, 25(3), 846853.

Deleuze, G. (1962/2006). Nietzsche and philosophy. Columbia University Press.

Fanon, F. (2008). Black Skin, White Masks (R. Philcox, trans.) New York: Grove Press.

Foucault, M. (1978). The History of Sexuality: An Introduction (Trans. R. Hurley). New York, NY: Pantheon Books. Original edition 1976.

Foucault, M. (1993). About the beginning of the hermeneutics of the self: Two lectures at Dartmouth. Political theory, 21(2), 198-227.

Haslanger, S. (2019). Disciplined Bodies and Ideology Critique. Glass Bead, 2(1).

Haslanger, S. (2020). Cognition as a social skill. Australasian Philosophical Review, 3(1), 525 .

Jaeggi, R. (2008). Rethinking ideology. In B. de Bruin \& C. F. Zurn (Eds.), New waves in political philosophy (pp. 63-86). Basingstoke: Palgrave McMillan.

James, W. (1896/1979). The will to believe and other essays in popular philosophy (Vol. 6). Harvard University Press.

Jost, J. T. (2020). A theory of system justification. Harvard University Press.

Mameli, M. (2001). Mindreading, mindshaping, and evolution. Biology and Philosophy, 16(5), 595-626.

Maiese, M. (2021). Mindshaping, Enactivism, and Ideological Oppression. Topoi, 1-14.

Maiese, M., \& Hanna, R. (2019). The mind-body politic. Springer.

Piketty, T. (2020). Capital and ideology. Harvard University Press.

Sankaran, K. (2020). What's new in the new ideology critique?. Philosophical Studies, 177(5), 1441-1462.

Shelby, T. (2003). Ideology, racism, and critical social theory. The Philosophical Forum, 34(2), 153-188.

Slaby, J. (2016). Mind invasion: situated affectivity and the corporate life hack. Frontiers in Psychology, 7, 266. 
Stanley, J. (2015). How propaganda works. Princeton University Press.

Price, H. (2004). Naturalism without representationalism. Naturalism in question, 71-88.

Zmigrod, L. (2020). The role of cognitive rigidity in political ideologies: theory, evidence, and future directions. Current Opinion in Behavioral Sciences, 34, 34-39.

Zmigrod, L. (2021). A neurocognitive model of ideological thinking. Politics and the Life Sciences, 40(2), 224-238.

Zmigrod, L. (2022). A Psychology of Ideology: Unpacking the Psychological Structure of Ideological Thinking. Perspectives on Psychological Science. https://doi.org/10.31234/osf.io/ewy9t.

Zmigrod, L., Eisenberg, I. W., Bissett, P. G., Robbins, T. W., \& Poldrack, R. A. (2021). The cognitive and perceptual correlates of ideological attitudes: a data-driven approach. Philosophical Transactions of the Royal Society B, 376(1822), 20200424.

Zmigrod, L., \& Goldenberg, A. (2021). Cognition and emotion in extreme political action: individual differences and dynamic interactions. Current Directions in Psychological Science, 0963721421993820.

Zmigrod, L., Rentfrow, P. J., \& Robbins, T. W. (2018). Cognitive underpinnings of nationalistic ideology in the context of Brexit. Proceedings of the National Academy of Sciences, 115(19), E4532-E4540.

Zmigrod, L., Rentfrow, P. J., \& Robbins, T. W. (2019). Cognitive inflexibility predicts extremist attitudes. Frontiers in psychology, 10, 989.

Zmigrod, L., Rentfrow, P. J., \& Robbins, T. W. (2020). The partisan mind: Is extreme political partisanship related to cognitive inflexibility?. Journal of Experimental Psychology: General, 149(3), 407.

Zmigrod, L., Rentfrow, P. J., Zmigrod, S., \& Robbins, T. W. (2019). Cognitive flexibility and religious disbelief. Psychological research, 83(8), 1749-1759.

Zmigrod, L., \& Tsakiris, M. (2021). Computational and neurocognitive approaches to the political brain: key insights and future avenues for political neuroscience. Philosophical Transactions of the Royal Society B, 376(1822), 20200130.

Zmigrod, L., Zmigrod, S., Rentfrow, P. J., \& Robbins, T. W. (2019). The psychological roots of intellectual humility: The role of intelligence and cognitive flexibility. Personality and Individual Differences, 141, 200-208. 